\title{
Cotas e desempenho acadêmico na UFBA: um estudo a partir dos coeficientes de rendimento
}

\author{
Adriano de Lemos Alves Peixoto \\ Elisa Maria Barbosa de Amorim Ribeiro \\ Antônio Virgilio Bittencourt Bastos \\ Maria Cecilia Koehne Ramalho
}

Resumo: Um debate recorrente em torno das cotas na universidade é a possibilidade do cotista obter rendimento satisfatório a despeito das diferenças no seu processo de formação anterior ao ingresso na Universidade. O objetivo deste estudo é comparar o desempenho de alunos cotistas e não cotistas da Universidade Federal da Bahia (UFBA), reunindo evidências que possam embasar ações institucionais no sentido de assegurar sólida formação a todos os seus alunos. A amostra foi por composta por todos os alunos ativos $(\mathrm{N}=26.175)$ matriculados. As análises indicam desempenho superior de não cotistas, sendo a magnitude da diferença $6,81 \%(\mathrm{~F}=348,114, \mathrm{p}<.000)$ quando os dois grupos são diretamente comparados. Quando separados por área de conhecimento, os cotistas apresentam desempenho superior em cursos das áreas de artes e humanidades de média e baixa concorrência. O déficit na formação básica, principalmente no domínio da matemática, aparece como um possível fator de influência nesta diferença de desempenho. Os resultados sugerem um fenômeno complexo e multifacetado. Para além das disputas ideológicas é preciso intervir nesta disparidade para uma efetiva inclusão dos cotistas na universidade.

Palavras-chave: Ação afirmativa. Desempenho acadêmico. Cotas. Avaliação.

\section{Affirmative policies and academic performance in a brazilian public university}

Abstract: An important and ongoing debate among academia and policy makers is about how good is the academic performance of students targeted by affirmative policies when compared to their fellows at the university. This study seeks to compare academic performance of two groups of students, beneficiary and non-beneficiary of affirmative action policy at Universidade Federal da Bahia (UFBA), a Brazilian public university. The sample was composed with all students currently enrolled at the university $(\mathrm{N}=26.175)$. The results suggest that non-beneficiary students have a higher academic performance when compared to beneficiaries. The difference between this two groups is $6,81 \%(\mathrm{~F}=348,114, \mathrm{p}<.000)$. When we split the group of students according to their under graduation course the differences get clearer with beneficiaries outperforming in arts and social sciences while non-beneficiaries outperform in health and engineering. The results suggest that this is a complex and multidetermined phenomenon where a lack of basic knowledge in math combined with problems arising from poor schooling explains differences in academic performance. Beyond ideological disputes it is necessary to intervene in this situation in order to guarantee an effective social inclusion and a good and solid education to all.

Key words: Affirmative action. Academic performance. Social/racial quota. Assessment. 


\section{Apresentação}

A adoção de políticas afirmativas pelas universidades públicas no Brasil foi resultado de um longo processo de militância de grupos minoritários dentro e fora das universidades. Principalmente ligados ao movimento negro, a ênfase destes atores estava na equiparação de oportunidades no acesso ao ensino superior e ao mercado de trabalho. Diante do objetivo de reduzir a desigualdade estampada nos censos sócio-demográficos, a reserva de vagas constituiu-se como estratégia concreta de reparação e promoção da igualdade entre grupos étnicos (MOEHLECKE, 2002; OLIVEN, 2011). É nessa perspectiva que a discussão da inclusão social nas universidades tem sido pensada, principalmente em termos de ampliação do acesso e/ou de diversificação na política de admissão de alunos tendo como base a proporção de participação dos grupos que compõem a sociedade nos tipos de instituição (pública ou privada) e nas carreiras mais disputadas pelos estudantes (SCHWARTZMAN, 2008).

$\mathrm{Na}$ Universidade Federal da Bahia (UFBA) este processo de inclusão ganha impulso a partir de 2002 com o programa Universidade Nova que, entre outras ações, estabeleceu a reserva de vagas para alunos pretos e pardos oriundos de escola pública. A efetivação desta proposta foi produto das discussões de um grupo de trabalho (GT) instituído neste mesmo ano com o objetivo de elaborar e propor a política de ações afirmativas na universidade. O GT realizou um levantamento da demanda e classificação nos vestibulares compreendidos entre o período de 1998 a 2002 constatando que embora $55 \%$ dos candidatos fossem negros e pardos, e $40 \%$ provenientes de escola pública, menos de $30 \%$ de negros e pardos e uma proporção inferior a $10 \%$ de alunos de escola pública ingressaram em cursos de grande concorrência como Direito, Odontologia e Medicina. Esse conjunto de dados evidenciou como principal objetivo da política afirmativa a ampliação do acesso de grupos em desvantagem a cursos onde foi identificada maior incongruência entre a demanda no vestibular e o perfil dos classificados. Além da reserva de vagas, o programa proposto pelo GT abrangeu ainda outras ações e atividades relacionadas com a preparação para o vestibular, permanência na universidade e pós-permanência (egressos).

A política de ações afirmativas da universidade foi aprovada em julho de 2004, através da resolução $n^{\circ} 01 / 04$ elaborada pelo Conselho de Ensino, Pesquisa e Extensão (CONSEPE). Em 2014 esse programa completará dez anos desde a sua implementação sendo um excelente momento para a comunidade universitária refletir sobre seus acertos, seus erros e decidir que rumos o programa deve tomar nos anos que se seguem. É importante reconhecer que 
existem agendas políticas e ideológicas muito fortes cristalizadas nos dois polos que normalmente acompanham esta discussão - os que são contrários e os que são favoráveis às cotas - fazendo com que o debate em torno desse tema seja sempre muito difícil. A esse respeito, Santos (2013) reconhece que mesmo que grande numero de instituições de ensino superior (IES) públicas tenham adotado algum tipo de ação afirmativa, elas raramente tornam público seus resultados com receio dos eventuais impactos destes dados na aceitação social da política de cotas.

Sem procurar defender ou justificar uma ou outra posição, os resultados apontam para uma realidade mais complexa e multifacetada do que a simples oposição entre prós e contra é capaz de supor. Enfrentar esta situação e oferecer soluções concretas e efetivas às diversas demandas sociais faz parte da própria gênese da universidade pública brasileira. Assim, este estudo pretende retomar a discussão de desempenho e cotas na UFBA, já abordada por pesquisadores como Santos e Queiroz (2013), Queiroz e Santos (2010) e Guimarães, Costa e Almeida Filho (2011), no intuito de contribuir para a reflexão sobre os dez anos de implementação da política de cotas nesta universidade.

Ao longo de nossas análises procuramos responder a três perguntas principais: Existem diferenças de desempenho entre cotistas e não cotistas com base no coeficiente de rendimento (CR)? Existem diferenças de desempenho em função do período de ingresso na universidade? Existem diferenças de desempenho em função do curso de graduação? Visando responder a estas questões, o presente estudo encontra-se dividido em quatro seções além desta apresentação. Na segunda seção, encontramos uma revisão de literatura com estudos que discutem o desempenho de cotista com base em indicadores e medidas acadêmicas. $\mathrm{Na}$ sequência apresentamos os procedimentos metodológicos que guiaram este estudo. Na quarta seção, apresentamos e discutimos os principais resultados. Já a última seção trata das principais conclusões deste trabalho.

\section{Revisão da literatura}

Os estudos iniciais sobre ações afirmativas no ensino superior destacavam o papel do curso universitário na estratégia de inserção social e a assunção de posições privilegiadas no mercado de trabalho, ao mesmo tempo que evidenciavam quais grupos sociais em termos de raça, renda e gênero tinham acesso a este espaço considerado elitista e privilegiado. Em uma atmosfera instigada por movimentos sociais em prol da inserção do negro e de outras minorias na universidade, estudos passam a demonstrar e questionar a predominante presença de estudantes brancos provenientes de escolas particulares nas universidades 
públicas (p.ex. CARVALHO, 2001; MUNANGA, 2001; CARVALHO; SEGATO, 2002; QUEIROZ, 2001; MOEHLECKE, 2002; MOEHLECKE, 2004).

A partir das experiências de implantação de políticas afirmativas em universidades públicas os estudos passaram a descrever o processo de implementação das cotas e os diferentes critérios e formas de ingresso (p.ex. CORDEIRO, 2012; QUEIROZ; SANTOS, 2012; SILVA, 2009; BERALDO; MAGRONE, 2012; FERRAZ, 2012; JOSÉ et al., 2012; MACIEL, 2012; ANJOS, 2012; SILVEIRA; SILVEIRA, 2012; TRAGTENBERG, 2012; CIRQUEIRA; GONÇALVES; RATTS, 2012) deflagrando intensos e calorosos debates sobre cotas raciais e/ ou sociais (SANTOS, 2008; TESSLER, 2008) que passa a ser o elemento mais visível dessa discussão.

A inserção dos cotistas no contexto universitário, a partir de 2002, exacerba o debate sobre os desdobramentos desta política e dos impactos de sua adoção. Este debate se reflete nos estudos que passam a abordar: a percepção avaliativa dos diferentes atores no contexto universitário sobre as cotas (MENIN, 2008; PINHEIRO, 2010); a convivência de classes e grupos étnicos na universidade (CICALO, 2012); o debate em torno da meritocracia e isonomia (TARVANARO, 2009); o relato de estudantes cotistas sobre sua trajetória na graduação (VALENTIM; CANDAU, 2012); o viés do debate midiático sobre as ações afirmativas (FERES JUNIOR; CAMPOS; TOSTE DAFLON, 2011; VIANA; BENTES, 2011; FERES JÚNIOR; TOSTE DAFLON, 2012); e as dificuldades de permanência na universidade (CARDOSO, 2008; ZARPELON; CORDEIRO, 2009). Durante todo este percurso são encontrados estudos de caráter avaliativo, comparando o desempenho de estudantes cotistas e não cotistas no vestibular e na graduação confirmando a importância dessa temática para a discussão sobre a política de cotas em todo o país.

Após a decisão do Supremo Tribunal Federal sobre a constitucionalidade das políticas de ação afirmativa em 2012 os estudos sobre desempenho adquirem maior visibilidade. No primeiro semestre de 2013, voltam a ser frequentes notícias baseadas em pesquisas sobre o desempenho comparativo dos cotistas e não cotistas no vestibular e na graduação ainda que muitos apresentam resultados nitidamente contraditórios: "Mercadante comemora nota de corte cotistas" (MOURA, 2013); "Na Unifesp, cotistas e não cotistas têm média igual" (LORDELO, 2013); "Rendimento de cotistas em universidades caiu com o passar do tempo" (MARENCO, 2013); e "Cotistas têm desempenho inferior entre os universitários" (FRAGA, 2013).

Diante da importância deste debate, da sua nítida apropriação política e da natureza aparentemente contraditória dos resultados torna-se imperiosa 
a necessidade de ampliar os estudos sobre este tema assim como avaliar os diferentes delineamentos metodológicos, a composição das amostras e formas de estimação do desempenho utilizados em cada pesquisa. Embora a maioria dos estudos sobre desempenho acadêmico de cotistas e não cotistas utilizem o coeficiente de rendimento (CR) como parâmetro principal, há uma variedade de enfoques e recortes nos dados (alguns mais e outros menos rigorosos) que alteram o alcance das interpretações e conclusões a eles subjacentes.

Cunha (2006) comparou a demanda por vagas e o desempenho entre 1969 estudantes cotistas e não cotistas no primeiro vestibular com sistema de cotas na Universidade de Brasília - UNB. Além disso, analisou o desempenho dos dois grupos no primeiro semestre e em que medida esse desempenho foi predito pelas notas no vestibular. Sua análise mostrou que apesar das cotas estudantes cotistas tendem a procurar cursos menos concorridos. Na área de ciências e de saúde, a demanda dos alunos do sistema universal (não cotistas) chegou a ser $150 \%$ maior do que a dos cotistas, caracterizando um comportamento de auto-seleção destes últimos.

Já a comparação do desempenho dos dois grupos tanto no vestibular como no CR do primeiro semestre encontrou rendimento superior dos candidatos não cotistas. Entretanto, o desempenho no vestibular não necessariamente é um bom preditor para o desempenho na universidade para todos os cursos. Para a autora, a exigência de atingir escores mais elevados para estudantes ingressos pelo sistema universal torna mais explícita a diferença do impacto da formação anterior no desempenho dos dois grupos de alunos.

Um estudo realizado por Waltenberg e Carvalho (2012) comparou o desempenho cotistas e não cotistas na prova de conhecimentos específicos do Exame Nacional de Desempenho de Estudantes (ENADE) de 2008. O estudo analisou dados de 167.704 concluintes de instituições públicas e privadas, o que representa $33,6 \%$ dos concluintes neste ano. A análise combinou dados sócio demográficos à distribuição das notas no exame nos diferentes grupos. Os resultados mostram que nas instituições privadas não foram observadas diferenças significativas de desempenho, com exceção dos cursos de alto prestígio, nos quais os não cotistas apresentaram desempenho mais elevado. Nas universidades federais, foi encontrada uma diferença de desempenho de 8,2\% na nota do ENADE quando comparado os dois grupos. Apesar da diferença, os autores concluem que o objetivo de inserção de grupos minoritários na universidade foi atingido, considerando o resultado encontrado como um ônus necessário.

Mendes Junior (2013) realizou um estudo sobre desempenho de alunos cotistas e não cotistas na Universidade do Estado do Rio de Janeiro (UERJ) tendo 
como parâmetros: CR médio entre 2006 e 2009 (para ingressantes em 2005); os CRs médios acumulados de alunos formados (2005 a 2012); a proporção de concluintes; e as taxas de evasão. Considerando todos os cursos, os cotistas apresentaram um CR médio 6,5\% menor do que os não cotistas no período compreendido entre 2006 e 2009 foi de 6,5\%. Quando a análise é focada nos cursos mais concorridos a diferença aumenta na proporção em que aumenta o grau de dificuldade do curso chegando à $16 \%$ no caso dos cursos de maior concorrência quando observado o grupo de concluintes. Além disso, o desempenho dos não cotistas foi mais elevado em $80 \%$ dos cursos. Já a observação da trajetória dos CRs médios ao longo dos quatro anos não indica uma redução da diferença entre os CRs dos dois grupos com o passar do tempo.

Já o estudo de Queiroz e Santos (2006) comparou o desempenho de estudantes da UFBA ingressos nos dois semestres de 2005. Os autores utilizaram a proporção de alunos por curso com coeficiente situado entre duas faixas: 5,1 a 10 e 7,0 a 10. Na primeira faixa, os cotistas apresentaram rendimento superior ou equivalente em 11 dos 18 cursos mais concorridos da UFBA. Já na segunda, os não cotistas apresentaram rendimento superior aos cotistas. Em um trabalho mais recente, Queiroz e Santos (2010), identificam um padrão similar nos resultados quando analisados os alunos matriculados na UFBA em 2007 e 2008.

Guimarães, Costa e Almeida Filho (2011) compararam o desempenho de estudantes da UFBA matriculados no campus de Salvador. Os alunos foram divididos em três grupos: não beneficiários - sem direito à reserva de vagas; beneficiários não efetivos - entrariam mesmo sem as cotas por conta do desempenho elevado; e beneficiários efetivos - o ingresso foi viabilizado efetivamente pelo sistema de cotas. A medida utilizada foi o CR padronizado (onde cada CR subtraído da média e dividido pelo desvio-padrão dos CR do total). Os resultados não indicaram diferenças significativas entre os grupos de não beneficiários e beneficiários não efetivos, mas houve diferença entre o grupo de beneficiários efetivos e os demais. Na sequencia, os pesquisadores passaram a considerar o desempenho relativo dos estudantes, agrupando os escores do vestibular e os CR em quintis para comparar a trajetória dos diferentes grupos nos dois momentos (vestibular e graduação). Neste recorte o desempenho relativo dos beneficiários efetivos foi sempre igual ou acima dos não beneficiários. Ou seja, os alunos que ingressam por cotas tem um maior espaço para melhorar seu desempenho do que aqueles que são selecionados pelo sistema universal. Quando avaliados sobre o parâmetro de Região de Pior de Pontuação os alunos beneficiários dos cursos de alta demanda apresentam maior dificuldade de melhorar o desempenho relativo (GUIMARÃES; COSTA; ALMEIDA FILHO, 2011). 
O conjunto das evidências disponíveis, principalmente aquelas baseados em amplos estudos quantitativos, apontam de forma consistente para a existência um gap de desempenho entre alunos cotistas e não cotistas principalmente nos cursos com grande concorrência e da área de exatas. Este fato não deveria surpreender aos observadores, já que a diferença de desempenho é ela uma das justificativas para a existência das cotas. Assim, cumpre compreender a natureza e a dinâmica desta realidade e buscar oferecer soluções para sua superação. Por outro lado, resultados aparentemente divergentes, indicando não haver diferenças ou maior rendimento entre estes grupos, em geral são encontrados a partir de amostras parciais ou recortes metodológicos peculiares.

\section{Procedimentos metodológicos}

Todos os dados utilizados nesta análise foram fornecidos pela Superintendência de Tecnologia de Informação da UFBA, sendo extraídos do sistema acadêmico (SIAC) da universidade que é responsável pelo registro das notas dos alunos. Foi tomado como base de análise o CR que é calculado para todos os alunos do curso a partir das notas obtidas e carga horária das disciplinas cursadas.

No SIAC as cotas aparecem em duas situações distintas, como forma de classificação que decorre da maneira como o aluno se inscreveu no vestibular e como forma de ingresso que decorre da maneira como ele efetivamente se matricula na universidade após ser aprovado no processo seletivo. Essas duas formas de classificação não são necessariamente coincidentes na medida em que alunos que se inscrevem no vestibular em um tipo de categoria podem ser selecionados, em função da disponibilidade de vagas, em outro tipo de categoria. Para efeito das análises aqui apresentadas nós utilizaremos a categorização conforme a forma de ingresso do aluno.

O sistema de seleção da UFBA contempla seis categorias de cotas distintas: Categoria A: (cota) candidatos de escola pública que se declararam pretos ou pardos; Categoria B: (cota) candidatos de escola pública de qualquer etnia ou cor; Categoria C: (sem cota) candidatos de escola particular que se declararam pretos ou pardos; Categoria D: (cota) candidatos de escola pública que se declararam índio-descendentes; Categoria E: (sem cota) todos os candidatos, qualquer que seja a procedência escolar e a etnia ou cor; Categoria F: (cota) índios aldeados ou quilombolas.

A partir destas categorias primárias criamos uma nova variável que agrupa os alunos em duas categorias novas: Cotistas (formado pelas categorias de 
ingresso A, B, D e F) e Não Cotistas (formada por alunos das categorias C e E) que tomamos como base para todas as análises.

Nossa amostra é composta por todos os alunos ativos da UFBA que apresentam classificação por forma de ingresso com base no sistema de cotas $(\mathrm{N}=$ 26.175). É importante observar que a classificação de ingresso não se aplica a alunos oriundos de transferência interna e externa, portadores de diploma de nível superior e alunos especiais.

Para os alunos que ingressaram em 2012.2 utilizamos o CR que foi calculado ao final deste semestre letivo. Para todos os demais, utilizamos o CR calculado com base nas informações consolidadas ao final do semestre de 2012.1. Eliminamos da análise todos os alunos da amostra original que apresentaram CR igual a zero $(\mathrm{N}=1.699)$, que são, principalmente, aqueles casos de reprovação por falta e ausência de notas no sistema.

\section{Principais resultados}

Iniciamos nossa análise buscando responder a uma pergunta de caráter mais amplo: existe diferença entre cotistas e não cotistas com base no CR? que tem como objetivo estabelecer uma compreensão básica para a distribuição das notas entre estes dois grupos. Para responder a essa pergunta iniciamos comparando os coeficientes de rendimentos dos dois grupos, cotistas e não cotistas.

Os resultados mostram que quando comparamos os alunos de forma conjunta o desempenho dos alunos não cotistas é superior ao dos cotistas em $6,81 \%$, sendo esta diferença estatisticamente significativa $(\mathrm{F}=348,114$, $\mathrm{p}<.000$ ). Os resultados gerais encontrados são absolutamente compatíveis com aqueles relatados por Mendes Junior (2013) para a UERJ. Os desvios padrão nos mostram que existe menor dispersão dos CRs dos cotistas quando comparados com os não cotistas, ou seja, uma menor variação nas notas ainda que a diferença seja muito pequena.

É importante observar que em função do elevado tamanho de N, mesmo mínimas diferenças entre os escores podem se mostrar estatisticamente significativas. Por outro lado, como os resultados encontrados podem sofrer a influência de grupos específicos de alunos com desempenhos extremos (positivos ou negativos) distorcendo as médias, ampliamos a análise de modo a incluir indicadores de dispersão dos resultados mais gerais e, assim, comparamos os resultados nos quartís 25, 50 (mediana) e 75. Neste caso, os CRs correspondem à "notas de corte", notas que estabelecem um limite entre os grupos. 
Tabela 1 - Estatística básica para todos os alunos ativos segundo categoria

\begin{tabular}{|c|c|c|c|c|c|c|c|c|}
\hline \multirow{2}{*}{ Cota } & \multirow{2}{*}{$\mathbf{N}$} & \multirow{2}{*}{ Média } & \multirow{2}{*}{ Desvio Padrão } & \multicolumn{3}{|c|}{ Percentis } & \multirow{2}{*}{$\mathbf{F}$} \\
\cline { 5 - 7 } & & & & 25 & Mediana (50) & 75 & & Não cotista \\
\cline { 5 - 7 } & 15030 & 6.5 & 1.80 & 5.60 & 7.0 & 7.8 & & \\
\hline Cotista & 11145 & 6.1 & 1.76 & 5.10 & 6.4 & 7.4 & & \\
\hline & & & & & & & & \\
\hline
\end{tabular}

Os resultados confirmam que o desempenho geral dos não cotistas é superior ao dos cotistas em todos os níveis, com escores que variam de 0,4 a 0,6 pontos (numa escala de 10 pontos), considerando-se a média global ou os quartis. Quando nós separamos os dois grupos e comparamos os alunos de pior desempenho (25\%) a diferença de CR é de 9,8\%. Um valor similar é identificado quando dividimos os grupos na metade. Já quando olhamos para a porção superior da amostra (quartil 75) percebemos que existe uma redução nessa diferença sugerindo que o desempenho dos melhores alunos cotistas se aproxima do desempenho dos melhores alunos não cotistas. Esse resultado é compatível com aquele obtido por Guimarães, Costa e Almeida Filho (2011) que mostra não existirem diferenças entre grupos de melhor preparo (não beneficiários e não cotistas).

Deste ponto passamos a buscar a resposta para nossa segunda questão: Existe diferença entre cotistas e não cotistas em função do semestre cursado?

Essa indagação tem sua base na ideia de que eventuais diferenças existentes no início do curso, em função das deficiências do ensino médio, poderiam a ser superadas à medida que os alunos avançam na universidade. Ou seja, se esta suposição estiver correta, deveríamos observar uma diminuição da diferença entre os dois grupos ao longo do tempo. Para responder à esta pergunta separamos os dois grupos em função do período de ingresso na universidade e comparamos os CRs pela média, quartil 25 , mediana e quartil 75 , seguindo o padrão da questão anterior. No momento em que coletamos os dados, os alunos ativos mais antigos na universidade haviam ingressado em 2005.1 perfazendo um total de dezesseis semestres de comparação (de 2005.1 até 2012.2).

A análise mostra que os não cotistas têm um desempenho superior em relação aos cotistas para todos os marcadores de distribuição analisados (médias, mediana e quartís) em trezes dos dezesseis semestres. Nos demais semestres (2005.2, 2006.1 e 2006.2), os desempenhos são tão próximos, menores do que $5 \%$, que diferenças não podem ser estabelecidas. 


\section{Tabela 2 - Diferença de desempenho entre não cotistas e cotistas conforme período de ingresso}

\begin{tabular}{|c|c|c|c|c|c|c|c|c|}
\hline \multirow{2}{*}{ Ingresso } & \multirow{2}{*}{ Cotas } & \multirow{2}{*}{ Média } & \multirow{2}{*}{$d p$} & \multicolumn{3}{|c|}{ Percentis } & \multirow{2}{*}{$\mathbf{t}$} & \multirow{2}{*}{$\mathbf{P}$} \\
\hline & & & & 25 & 50 & 75 & & \\
\hline \multirow{2}{*}{2005.1} & Não Cotista & 6,0 & 1,43 & 5,0 & 5,9 & 7,1 & \multirow{2}{*}{3,017} & \multirow{2}{*}{,003 } \\
\hline & Cotista & 5,3 & 1,23 & 4,6 & 5,3 & 5,9 & & \\
\hline \multirow[b]{2}{*}{2005.2} & Não Cotista & 5,5 & 1,13 & 4,7 & 5,5 & 6,2 & \multirow[b]{2}{*}{,476 } & \multirow{2}{*}{,634 } \\
\hline & Cotista & 5,5 & 1,16 & 4,7 & 5,4 & 6,2 & & \\
\hline \multirow{2}{*}{2006.1} & Não Cotista & 5,9 & 1,62 & 4,7 & 5,7 & 7,4 & \multirow{2}{*}{1,147} & \multirow{2}{*}{,252 } \\
\hline & Cotista & 5,7 & 1,22 & 4,9 & 5,6 & 6,7 & & \\
\hline \multirow{2}{*}{2006.2} & Não Cotista & 5,6 & 1,11 & 4,9 & 5,7 & 6,3 & \multirow{2}{*}{,- 588} & \multirow{2}{*}{,557 } \\
\hline & Cotista & 5,7 & 1,11 & 5,0 & 5,7 & 6,3 & & \\
\hline \multirow{2}{*}{2007.1} & Não Cotista & 6,5 & 1,49 & 5,6 & 6,6 & 7,7 & \multirow{2}{*}{3,932} & \multirow{2}{*}{,000 } \\
\hline & Cotista & 6,1 & 1,42 & 5,3 & 6,1 & 7,2 & & \\
\hline \multirow{2}{*}{2007.2} & Não Cotista & 6,7 & 1,45 & 5,7 & 6,9 & 8,0 & \multirow{2}{*}{4,158} & \multirow{2}{*}{,000 } \\
\hline & Cotista & 6,2 & 1,34 & 5,4 & 6,2 & 7,4 & & \\
\hline \multirow{2}{*}{2008.1} & Não Cotista & 7,0 & 1,38 & 6,1 & 7,3 & 8,1 & \multirow[b]{2}{*}{5,881} & \multirow{2}{*}{,000 } \\
\hline & Cotista & 6,6 & 1,49 & 5,7 & 6,9 & 7,7 & & \\
\hline & Não Cotista & 7,0 & 1,30 & 6,3 & 7,2 & 7,9 & & \\
\hline 2008.2 & Cotista & 6,3 & 1,36 & 5,5 & 6,5 & 7,3 & ,114 & , 000 \\
\hline 20091 & Não Cotista & 6,8 & 1,66 & 5,8 & 7,1 & 8,0 & 5.401 & 000 \\
\hline 2000.1 & Cotista & 6,4 & 1,59 & 5,5 & 6,7 & 7,6 & 5,401 & , 000 \\
\hline 20092 & Não Cotista & 6,8 & 1,49 & 5,9 & 7,1 & 7,8 & 8732 & 000 \\
\hline & Cotista & 6,0 & 1,61 & 5,1 & 6,2 & 7,2 & $8, / 32$ & 然, \\
\hline 20101 & Não Cotista & 6,5 & 1,89 & 5,5 & 7,0 & 7,9 & 5533 & 000 \\
\hline 2070.1 & Cotista & 6,2 & 1,84 & 5,0 & 6,5 & 7,6 & 5,533 & (000 \\
\hline $2010 ?$ & Não Cotista & 6,6 & 1,68 & 5,9 & 7,0 & 7,8 & 8,376 & ( \\
\hline 2010.2 & Cotista & 5,9 & 1,85 & 4,8 & 6,1 & 7,3 & & (000 \\
\hline & Não Cotista & 6,1 & 2,01 & 5,0 & 6,6 & 7,6 & 986 & 000 \\
\hline 2011.1 & Cotista & 5,8 & 1,92 & 4,8 & 6,2 & 7,3 & 4,986 & , 000 \\
\hline 20112 & Não Cotista & 6,5 & 1,72 & 5,7 & 6,8 & 7,7 & 5,189 & 000 \\
\hline & Cotista & 6,0 & 1,61 & 5,2 & 6,2 & 7,2 & & (0) \\
\hline 20121 & Não Cotista & 6,7 & 2,00 & 5,8 & 7,2 & 8,0 & 6081 & > \\
\hline 2012.1 & Cotista & 6,2 & 2,10 & 5,2 & 6,7 & 7,7 & 6,981 & - \\
\hline 20122 & Não Cotista & 6.4 & 1.84 & 5.5 & 6.8 & 7.8 & $?$ & 10 \\
\hline 2012.2 & Cotista & 6,0 & 1,75 & 4,9 & 6,3 & 7,3 & 4,532 & (000 \\
\hline
\end{tabular}

$\mathrm{Dp}=$ desvio padrão. Os valores na tabela foram aproximados para facilitar sua compreensão

Neste ponto é importante observar que quanto mais tempo têm os estudantes na universidade, menor o tamanho deste grupo seja em função de evasão, seja em função da conclusão do curso fazendo com que o resultado seja mais sensível à pequenas variações nos escores. Por outro lado, alunos que ingres- 
saram em 2005 e 2006 já ultrapassaram o período médio de integralização em todos os cursos de graduação sendo possível supor tratar-se de um conjunto com características próprias de tempo, disponibilidade e dificuldade de acompanhamento dos estudos.

Quando nos voltamos para a diferença de escores por semestres os dados parecem sugerir que existem diferenças maiores quando comparamos ingressantes do primeiro com o segundo semestre do que quando a comparação se dá entre anos distintos. Este resultado em função do semestre de ingresso não é difícil de ser compreendido. Para os cursos que têm dupla entrada (primeiro e segundo semestre) essa separação se dá em função de diferenças de notas. Assim, os melhores alunos, cotistas e não cotistas, ficando para o segundo semestre os alunos com pior desempenho. Como a dispersão das notas entre não cotistas é menor em função da dupla concorrência a que são submetidos (do próprio vestibular e dos cotistas) isso faz com que seja maior a diferença entre os dois grupos, como já observado por Cunha (2006).

Para tornar esta relação mais facilmente percebida plotamos o resultado na forma de um gráfico onde localizamos no eixo do $\mathrm{Y}$ as diferenças de CRs.

\section{Gráfico 1 - Diferença de desempenho (em \%) entre não cotistas e cotistas conforme período de ingresso}

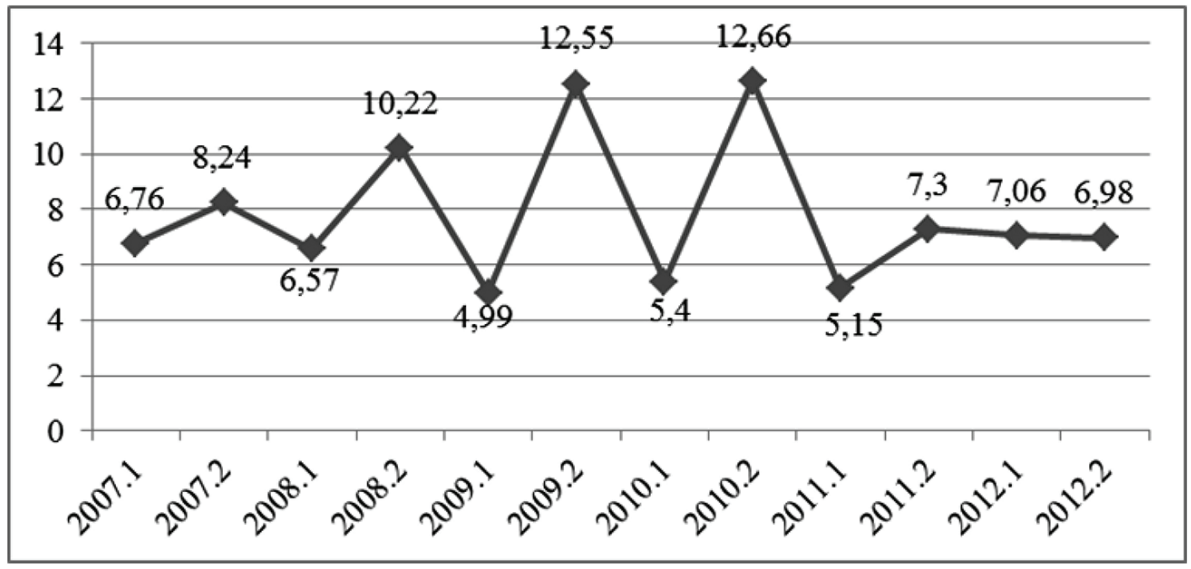

O caso dos semestres iniciais parece ser um pouco mais complexo. Aqui a diferença entre os dois grupos existe em um grau maior do que a média geral, mas ao mesmo tempo, observamos uma menor distância entre os CRs do primeiro e do segundo semestre, É possível que este resultado esteja mostrando que a diferença de escore entre os dois grupos sofre influência da evasão que exclui, 
logo dos semestres iniciais, alunos com maior dificuldade de permanência na universidade tendo como consequência a ampliação a diferenças dos resultados nos semestres mais adiantados do cursos. De toda sorte, esta é apenas uma suposição que exige um acompanhamento mais próximo em estudos posteriores visando compreender as dinâmicas em ação nesta situação específica.

Existe diferença entre cotistas e não cotistas em função do curso?

A resposta a esta pergunta nos leva à constatação de que a diferença entre cotistas e não cotistas é mais complexa e multifacetada do que a análise dos dados agregados permite supor, pois a depender do curso esta diferença pode se inverter (cotistas com desempenho superior ao de não cotista), ser irrelevante ou pode ser bastante expressiva. Nas tabelas abaixo apresentamos as principais diferenças entre os cursos. Iniciamos observando os cursos nos quais os cotistas têm um desempenho superior aos não cotistas. Para efeito de análise, consideramos que diferenças menores do que $5 \%$ são consideradas irrelevantes, pois estão dentro de margem de erro estatística usualmente aceita. Em resumo, os cotistas têm desempenho superior em 13 dos cursos analisados, sendo que a maior diferença $(16,56 \%)$ é observada em um curso de Letras.

Tabela 3 - Principais cursos onde o desempenho de cotistas é superior ao de não cotistas, diferença de escores em \%

\begin{tabular}{|c|c|c|c|c|}
\hline Curso & Classificaçăo & Médias & $\mathrm{dp}$ & Dif. \% \\
\hline \multirow{2}{*}{ Lic. em Des enho e Plástica } & Nä́o cotista & 6,0 & 2,35 & \multirow{2}{*}{13,03} \\
\hline & Cotista & 6,8 & 1,95 & \\
\hline \multirow{2}{*}{ Zootecnia } & Näo cotista & 5,1 & 1,70 & \multirow{2}{*}{12,06} \\
\hline & Cotista & 5,9 & 1,28 & \\
\hline \multirow{2}{*}{ Mus eologia } & Näo cotista & 6,0 & 2,16 & \multirow{2}{*}{11,58} \\
\hline & Cotista & 6,8 & 1,39 & \\
\hline \multirow{2}{*}{ Estatística } & Näo cotista & 4,4 & 1,95 & \multirow[b]{2}{*}{9,3} \\
\hline & Cotista & 4,8 & 1,61 & \\
\hline \multirow{2}{*}{ Lic. Em Teatro } & Näo cotista & 7,2 & 1,77 & \multirow{2}{*}{7,84} \\
\hline & Cotista & 7,9 & 1,64 & \\
\hline \multirow{2}{*}{ Gastronomia } & Nâo cotista & 7,3 & 1,89 & \multirow{2}{*}{7,63} \\
\hline & Cotista & 7,9 & 1,12 & \\
\hline \multirow{2}{*}{ Gênero e Diversidade } & Näo cotista & 6,0 & 2,04 & \multirow[b]{2}{*}{7,4} \\
\hline & Cotista & 6,5 & 1,53 & \\
\hline \multirow{2}{*}{ Secretariado Executivo } & Não cotista & 6,5 & 1,67 & \multirow[b]{2}{*}{6,57} \\
\hline & Cotista & 6,9 & 1,44 & \\
\hline \multirow{2}{*}{ Biblioteconomia } & Näo cotista & 6,7 & 1,90 & \multirow{2}{*}{5,51} \\
\hline & Cotista & 7,1 & 1,33 & \\
\hline \multirow{2}{*}{ Educação Física } & Näo cotista & 6,1 & 1,83 & \multirow{2}{*}{5,26} \\
\hline & Cotista & 6,5 & 1,83 & \\
\hline
\end{tabular}

Obs: Os valores na tabela foram aproximados para facilitar sua compreensão 
Na sequência podemos observar a mesma relação agora tendo por base os cursos onde os não cotistas têm um desempenho superior. Neste ponto dois aspectos principais chamam a nossa atenção: a) os não cotistas tem um desempenho superior em 38 cursos, quase o triplo em relação aos cotistas; b) o tamanho das diferenças é muito mais expressivo. Por exemplo, a diferença entre o desempenho na Engenharia de Controle e Automação de Processo (curso de melhor desempenho dos não-cotistas) é 3 vezes maior do que a diferença em Desenho e Plástica (curso de melhor desempenho dos cotistas).

Tabela 4 - Principais cursos onde desempenho de não cotistas é superior aos de cotistas, diferença de escores em \%

\begin{tabular}{|c|c|c|c|c|}
\hline Curso & Classificação & Médias & dp & Dif. $\%$ \\
\hline Eng. de Controle e Automação de & Não cotista & 6,1 & 1,97 & \multirow{2}{*}{41,24} \\
\hline Processo & Cotista & 4,3 & 2,08 & \\
\hline \multirow{2}{*}{ Computaçäo } & Năo cotista & 4,2 & 1,33 & \multirow{2}{*}{39,11} \\
\hline & Cotista & 3,0 & 2,00 & \\
\hline \multirow{2}{*}{ Engenharia de Produçäo } & Não cotista & 6,8 & 1,47 & \multirow{2}{*}{38,50} \\
\hline & Cotista & 4,9 & 1,80 & \\
\hline \multirow{2}{*}{ Engenharia Elétrica } & Não cotista & 7,0 & 1,49 & \multirow{2}{*}{31,02} \\
\hline & Cotista & 5,4 & 1,73 & \\
\hline \multirow{2}{*}{ Engenharia Mecânica } & Não cotista & 6,9 & 1,38 & \multirow{2}{*}{28,43} \\
\hline & Cotista & 5,4 & 1,52 & \\
\hline \multirow{2}{*}{ Engenharia Química } & Não cotista & 7,0 & 1,33 & \multirow{2}{*}{25,61} \\
\hline & Cotista & 5,6 & 1,61 & \\
\hline \multirow{2}{*}{ Engenharia de Computação } & Não cotista. & 5,5 & 1,86 & \multirow{2}{*}{23,90} \\
\hline & Cotista & 4,4 & 1,86 & \\
\hline \multirow{2}{*}{ Arquitetura e Urbanismo } & Não cotista & 7,1 & 1,48 & \multirow{2}{*}{21,12} \\
\hline & Cotista & 5,8 & 1,63 & \\
\hline \multirow{2}{*}{ Biotecnologia } & Năo cotista & 6,2 & 1,23 & \multirow{2}{*}{19,67} \\
\hline & Cotista & 5,2 & 1,61 & \\
\hline \multirow{2}{*}{ Oceanografia } & Näo cotista & 6,0 & 1,32 & \multirow{2}{*}{18,41} \\
\hline & Cotista & 5,1 & 1,52 & \\
\hline
\end{tabular}

Obs: Os valores na tabela foram aproximados para facilitar sua compreensão

Para os demais cursos $(\mathrm{N}=29)$ as diferenças entre os dois grupos é menor do que $5 \%$ ora com predomínio de um grupo ora de outro de forma equilibrada.

Diante deste conjunto de resultados ampliamos nossa análise para tentar melhor localizar de forma mais específica a diferença de desempenho entre estes dois grupos. A resposta tradicional à esta questão consiste em focar nos 
conhecidos problemas de formação dos alunos originários da escola pública. Entretanto, ainda que este seja um problema real com impactos diretos nos resultados observados, esta resposta não é suficiente para explicar o porquê do desempenho superior dos cotistas em alguns cursos, da mesma forma que não explicita as razões para o desempenho negativo em outros. Assim, voltamos nosso olhar em busca de características próprias dos cursos na tentativa de responder a esta questão.

A fim de tornar esta relação mais visível, incluímos duas novas variáveis nas nossas análises: área do curso (de acordo com o critério adotado no vestibular da UFBA) e uma medida prestígio social baseada na concorrência dos cursos. Tomamos a demanda do vestibular de 2012 como critérios para nossas comparações e classificamos os resultados de acordo com a distribuição de frequência encontrada. A partir destes resultados adotamos a seguinte classificação: cursos com concorrência menor ou igual à 1 , foram classificados como sem concorrência; aqueles onde a concorrência é maior do que 1 e menor ou igual a 3, baixa concorrência; maior do que 3 e menor do que 8 , média concorrência; maior ou igual a 8, alta. Excluímos desta análise a concorrência do curso de Medicina que, por ser muito alta, distorce os resultados. Iniciaremos nossa análise pelos cursos onde os cotistas têm um desempenho superior.

Tabela 5 - Número de cursos, por área e concorrência, no quais os alunos cotistas tem desempenho superior

\begin{tabular}{l|c|c|c|c|c}
\hline Concorrência Área & Exatas & $\begin{array}{c}\text { Biológicas } \\
\text { Saúde }\end{array}$ & $\begin{array}{c}\text { Filosofia } \\
\text { Humanidades }\end{array}$ & Letras & Artes \\
\hline Sem concorrência & & & & & 1 \\
\hline Baixa & 1 & & 4 & 1 & 3 \\
\hline Média & & 2 & 1 & & \\
\hline Alta & & & & & \\
\hline Total & 1 & $\mathbf{2}$ & $\mathbf{5}$ & $\mathbf{1}$ & $\mathbf{4}$ \\
\hline
\end{tabular}

Como é possível perceber, os cursos onde os cotistas têm um desempenho superior se caracterizam por serem predominantemente das áreas de artes e humanidades ( 8 de um total de 13 cursos, $61,5 \%$ do total) e por terem todos, de baixa ou média demanda social. 
Tabela 6 - Número de cursos, por área e concorrência, no quais os alunos não cotistas tem desempenho superior

\begin{tabular}{l|c|c|c|c|c}
\hline Concorrênciar Área & Exatas & $\begin{array}{c}\text { Biológicas } \\
\text { Saúde }\end{array}$ & $\begin{array}{c}\text { Filosofia } \\
\text { Humanidades }\end{array}$ & Letras & Artes \\
\hline Sem concorrência & & & & & \\
\hline Baixa & 3 & 1 & & 1 & 3 \\
\hline Média & 5 & 8 & 3 & & 1 \\
\hline Alta & 8 & 2 & 3 & & \\
\hline Total & 16 & 11 & 6 & 1 & 4 \\
\hline
\end{tabular}

Quando nos voltamos para os cursos onde o desempenho dos não-cotistas é superior, um quadro completamente distinto emerge. Aqui passamos a observar um predomínio dos cursos das áreas de exatas e biológicas (27 de um total de 38 cursos, $71,05 \%$ do total) e por serem, em sua maioria, cursos de alta demanda social (30 de um total de 38 cursos, 78,95\% do total). Este critério de demanda social também se aplica aos principais cursos das humanidades aqui localizados (Comunicação, Direito, Psicologia e Administração). A figura abaixo apresenta uma síntese dos resultados agregados das tabelas.

Figura 1 - Número de cursos, por área e concorrência, nos quais cada uma das categorias (cotistas e não cotistas) tem desempenho superior

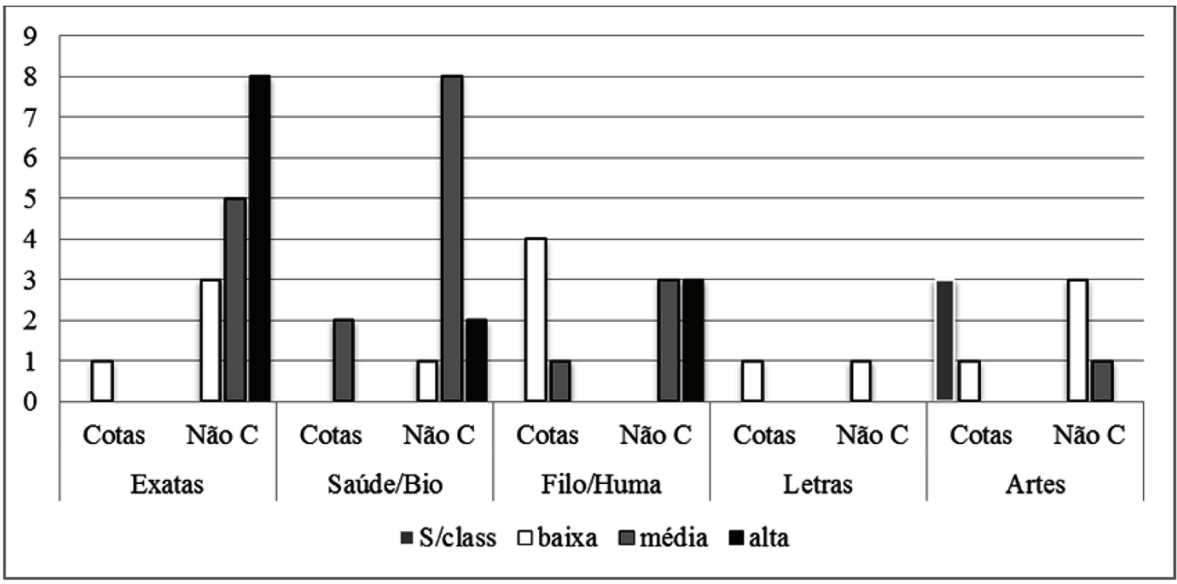


Os resultados nos sugerem que a diferença de desempenho entre alunos cotistas e não cotistas pode ser compreendida pela interação de dois fatores distintos: domínio de matemática, o que explica o tamanho e o predomínio da diferença entre os grupos nas engenharias, e demanda social que ao estabelecer níveis mais elevados de concorrência leva ao comportamento de auto seleção dos candidatos cotistas que não se candidatam aos cursos mais concorridos, como observado por Cunha (2006) na UnB. Entretanto, não devemos desconsiderar a possibilidade de que as diferenças observadas também estejam sob influência de outras variáveis como, por exemplo, diferentes padrões de avaliação dos alunos quando comparamos as engenharias e saúde, consideradas mais rigorosas, com as artes e humanidades, que tradicionalmente se valem de critérios que possibilitam um grau mais amplo de variação nas respostas neste quesito; e a uma diferença entre a natureza do conhecimento mais cumulativo nas exatas e biológicas do que nas humanas que ressaltaria as deficiências na formação básica. De qualquer forma, esta é uma questão ainda aberta à verificação empírica.

\section{Conclusão}

Os resultados encontrados sugerem que o desempenho comparativo entre grupos de estudantes deve ser compreendido como um fenômeno complexo e multideterminado, permitindo recortes bastante diferenciados dos dados empíricos para efeito de comparação. Para um adequado entendimento das questões relacionadas à diferença de desempenho entre alunos cotistas e não cotistas deve buscar analisar características específicas de cada curso, já que resultados agregados, apesar de bastante informativos, tendem a esconder elementos mais significativos. Esta estratégia de investigação permitiu identificar que os resultados parecem estar sobre controle de duas variáveis distintas: maior concorrência e domínio de conteúdos (matemática) e repertórios comportamentais específicos. Por sua vez, os resultados deste estudo estão perfeitamente alinhados àqueles resultados de pesquisa que têm o CR como base de comparação.

Se estas observações estão corretas, então devemos nos perguntar: o que é preciso fazer para superar as deficiências encontradas? Ainda que a reposta a esta questão não esteja no âmbito deste trabalho, ao longo do processo de análise pudemos identificar alguns elementos que precisam ser levados em consideração na busca de uma solução efetiva. Estas explicações são de caráter preliminar necessitando de estudos complementares para sua plena validação. 
Entretanto, parece não haver dúvidas de que a qualidade da escola pública é a principal explicação para o desempenho mais baixo na universidade do aluno cotista quando comparado com o não cotista. Este é um problema que afeta todo o país e que coloca limites efetivos às possibilidades de intervenção da universidade.

Por outro lado, muitos dos estudantes cotistas vêm de uma realidade socioeconômica precária, morando longe e enfrentando longos períodos de deslocamento de casa para a universidade sendo que muitos ainda precisam trabalhar para ajudar no sustento da família. Essa situação faz da permanência na universidade um desafio constante e coloca uma pressão sobre a instituição que precisa corresponder a essas necessidades com um número suficiente de bolsas (auxílios), vagas em residências universitárias e restaurante universitário, por exemplo, que facilitem a permanência e o pleno aproveitamento dos estudos destes mesmos alunos. Existe um terceiro grupo de problemas, que não devem ser subestimados, relacionado a questões da estrutura universitária que não se adaptou para dar conta dessa (nova) realidade do aluno cotista. Nessa categoria encontramos problemas como horários inadequados de funcionamento de órgãos administrativos e bibliotecas, acesso a material de estudo atualizado ou compatibilização de horário de disciplinas com exigências do trabalho.

A recorrente pergunta sobre o êxito das cotas tem sido respondida com base em diferentes parâmetros, muitos destes incongruentes com o seu objetivo original de inserir minorias sub-representadas em cursos universitários. A inclusão é o objetivo central, entendida como estratégia para estas minorias assumirem progressivamente espaços profissionais e o status econômico advindo destes, antes inacessíveis. Outros aspectos constantemente discutidos, como a dimensão de justiça e meritocracia, o desempenho dos cotistas na universidade e no mercado de trabalho e seus impactos para na qualidade da universidade, se situam no âmbito das implicações e consequências advindas da implementação da política para diferentes atores envolvidos.

Apesar da lei de cotas ter sido sancionada em agosto de 2012, a adesão a políticas desta natureza em algumas universidades brasileiras já acontece há 10 anos ou mais. A diferença de desempenho entre alunos cotistas e não cotistas sugere que ainda não tivemos mudanças efetivas na educação básica capazes de prover uma aprendizagem de qualidade a alunos da rede pública, e sinaliza que corremos o risco de uma política transitória se tornar permanente, pela incapacidade da sociedade de dar respostas satisfatórias para a questão da educação.

O conjunto de dados apresentados ao longo deste trabalho nos remete, finalmente, para o desafio posto à Universidade para assegurar uma aprendizagem 
significativa e o desenvolvimento de competências em todos os seus alunos, independente da origem, forma de ingresso e tipo de curso em que se insere. Sem entrarmos no mérito da qualidade da avaliação de desempenho realizada no âmbito dos diversos cursos (uma questão pedagógica insuficientemente debatida) há que se reconhecer que podemos avançar em desempenhos mais significativos em todos os grupos examinados. Para tanto há que se (re)pensar os processos de ensino-aprendizagem em suas características gerais e singulares a cada curso e área de conhecimento assim como se impõe pensarmos em estratégias apoio pedagógico e de orientação de carreira a alunos com carências de desempenho, a exemplo do que já acontece em universidades no exterior com importantes impactos no desempenho e nos indicadores de evasão.

\section{Referências}

ANJOS, J. C. G.A religiosidade afro-brasileira e a política de reserva de vagas na universidade Federal do Rio Grande do Sul. In: SANTOS, J. C. (Org.). Cotas nas universidades: análises dos processos de decisão. Salvador: Centro de Estudos Afro-Orientais, 2012. p. 41-76.

BERALDO, A, F.; MAGRONE, E.; Cotas na universidade Federal de Juiz de Fora: o começo (2004-2006). In: SANTOS, J. C. (Org.). Cotas nas universidades: análises dos processos de decisão. Salvador: Centro de Estudos Afro-Orientais, 2012. p. 99 - 136.

\section{CARDOSO, C. B. Efeitos da política de cotas na Universidade de}

Brasília: uma análise do rendimento e da evasão. 2008. Dissertação (Mestrado em Educação) - Universidade de Brasília, Brasília, 2008. Disponível em: $<$ http://www.redeacaoafirmativa.ceao.ufba.br/uploads/unb dissertacao_2008_CBCardoso.pdf $>$. Acesso em: 12 nov. 2013.

CARVALHO, J. J. As propostas de cotas para negros e o racismo acadêmico no Brasil. Sociedade e Cultura, Goiânia, v. 4, n. 2, p. 13-30, jul./dez. 2001.

CARVALHO, José Jorge; SEGATO, Rita Laura. Uma proposta de cotas para estudantes negros na Universidade de Brasília. Brasília: Departamento de Antropologia da UnB, 2002.

CICALO, A. Nerds and barbarians: race and class encounters through affirmative action in a Brazilian University. J. Lat. Am. Stud., Cambridge, v. 44, p. 235-260, 2012. 
CIRQUEIRA, D. M.; GONÇALVES, C. P.; RATTS, A. As marcas da travessia: o processo de implementação de ações afirmativas e cotas na universidade Federal de Goiás. In: SANTOS, J. C. (Org.). Cotas nas universidades: análises dos processos de decisão. Salvador: Centro de Estudos Afro-Orientais, 2012. p. 41-76.

CORDEIRO, M. J. J. A. Cotas para negros e indígenas na Universidade Estadual de Mato Grosso do Sul: processo histórico e político. In: SANTOS, J. C. (Org.). Cotas nas universidades: análises dos processos de decisão. Salvador: Centro de Estudos Afro-Orientais, 2012. p. 17-38.

CUNHA, E. M. P. Sistema universal e sistema de cotas para negros na Universidade de Brasília: um estudo de desempenho. 2006. 98 f. Dissertação (Mestrado em Educação) - Universidade de Brasília, Brasília, 2006.

FERES JÚNIOR, J.; CAMPOS, L. A.; TOSTE DAFLON, V. Fora de quadro: as ações afirmativas nas páginas d'O Globo. Contemporânea, São Carlos, v. 2, p. 61-83, 2011.

FERES JÚNIOR, J.; TOSTE DAFLON, V. Ação afirmativa na revista Veja: estratégias editoriais e o enquadramento do debate público. Revista Compolitica, Rio de Janeiro, v. 2, p. 66-91, 2012.

FERRAZ, M.P. T. Ações afirmativas na UNIFESP. In: SANTOS, J. C. (Org.). Cotas nas universidades: análises dos processos de decisão. Salvador: Centro de Estudos Afro-Orientais, 2012. p. 41-76.

FRAGA, E. Cotistas têm desempenho inferior entre universitários. Folha de S. Paulo, São Paulo, 28 abr. 2013. Disponível em: <http://www1.folha.uol. com.br/educacao/2013/04/1269984-cotistas-tem-desempenho-inferior-entreuniversitarios.shtml> Acesso em: 12 nov. 2013.

GUIMARÃES, A.S.; COSTA, L.; ALMEIDA FILHO, N. Inclusão social nas universidades brasileiras: o caso da UFBA In: As cores da desigualdade. Belo Horizonte: Fino Traço, 2011. v. 1. p. 19-41.

JOSÉ, W. D.; MEIRELES, A. M. B. M.; DIAS, G. E. D. D.; GALDINO, D.; GONÇALVES, A. L. A implantação da reserva de vagas na Universidade Estadual de Santa Cruz: uma trajetória de mobilização social. In: SANTOS, J. C. (Org.). Cotas nas universidades: análises dos processos de decisão. Salvador: Centro de Estudos Afro-Orientais, 2012. p. 41-76. 
LORDELO, C. Na Unifesp, cotistas e não cotistas têm média igual. Estadão, São Paulo, 19 maio 2013. Disponível em:< http://www.estadao.com.br/ noticia_imp.php?req=impresso,na-unifesp-cotistas-e-nao-cotistas-temmedia-igual-,1033240,0.htm.> Acesso em: 13 nov. 2013.

MACIEL, S. Ações afirmativas na Universidade Federal do Maranhão. R. bras. Est. pedag., Brasília, v. 93, n. 233, p. 7-8, jan./abr., 2012.

Manifesto em favor da lei de cotas e do estatuto de igualdade racial (2006). RDE: Revista de Direito do Estado, Rio de Janeiro, n. 3, p. 415-430, jul./ set., 2006.

MARENCO, D. Rendimento de cotistas em universidades caiu com o passar do tempo. Folha de S. Paulo, São Paulo, 28 abr., 2013. Disponível em: $<$ http://www1.folha.uol.com.br/educacao/2013/04/1270000-rendimento-decotistas-em-universidades-caiu-com-o-passar-do-tempo.shtml $>$. Acesso em: 12 nov. 2013.

\section{MENDES JUNIOR, A. A. F. Três ensaios sobre ações afirmativas no} ensino superior brasileiro: acesso, progressão e simulações de diferentes políticas de cotas para a Universidade do Estado do Rio de Janeiro. Dissertação (Pós-Graduação em Ciências Econômicas) - Universidade Federal Fluminense, Niterói, 2013.

MENIN, M. S. de S. et al. Representações de estudantes universitários sobre alunos cotistas: confronto de valores. Educação e Pesquisa, São Paulo, v. 34, n. 2, p. 255-272, 2008.

MOEHLECKE, Sabrina. Ação afirmativa: história e debates no Brasil. Cadernos de Pesquisa, São Paulo, n. 117, p. 197-217, nov., 2002.

MOEHLECKE, S. Fronteiras da igualdade no ensino superior: excelência e justiça racial. Tese (Doutorado em Educação) - Universidade de São Paulo, São Paulo, 2004. Disponível em: <http://www.redeacaoafirmativa. ceao.ufba.br/uploads/usp_tese_2004_SMoehlecke.pdf>. Acesso em: 12 nov. 2013.

MOURA, R. M. Mercadante comemora nota de corte de cotistas. Estadão, São Paulo, 10 jan. 2013. Disponível em: < http://www.estadao.com.br/ noticia_imp.php?req=geral,mercadante-comemora-nota-de-corte-decotistas, $982623,0 . \mathrm{htm}>$ Acesso em: 12 nov. 2013. 
MUNANGA, K. Políticas de ação afirmativa em benefício da população negra no Brasil: um ponto de vista em defesa de cotas. Sociedade e Cultura, Goiânia, v. 4, n. 2, p. 31-43, jul./dez., 2001.

OLIVEN, A. C. Ações afirmativas, relações raciais e política de cotas nas universidades: uma comparação entre os Estados Unidos e o Brasil. Educação, Porto Alegre, v. 30, n. 1, p. 29-51, 2011, Disponível em: <http:// revistaseletronicas.pucrs.br/ojs/index.php/faced/article/viewFile/539/375> Acesso em: 13 nov. 2013.

PINHEIRO, N. F. Cotas na Ufba: percepções sobre racismo, antirracismo, identidades e Fronteiras. Dissertação (Mestrado em Estudos Étnicos e Africanos) - Universidade Federal da Bahia, Salvador, 2010. Disponível em: <http:/www.redeacaoafirmativa.ceao.ufba.br/uploads/ufba dissertacao_2010_NFPinheiro.pdf $>$. Acesso em: 16 nov. 2013.

QUEIROZ, D. M. Raça, gênero e educação superior. Tese (Doutorado em Educação) - Universidade Federal da Bahia, Salvador, 2001. Disponível em: <http://www.redeacaoafirmativa.ceao.ufba.br/uploads/ufba_tese_2001_ DMQueiroz.pdf.>. Acesso em: 12 nov. 2013.

QUEIROZ, D. M.; SANTOS, J. T. Sistema de cotas: um debate. Dos dados à manutenção de privilégios e de poder. Educação \& Sociedade, Campinas, v. 27, n. 96, p. 717-737, 2006.

QUEIROZ, D. M.; SANTOS, J.T. Ações afirmativas para negros no ensino superior e desempenho de estudantes. In: COSTA, L. F.; MESSEDER, M. L. (Org.). Educação, multiculturalismo e diversidade. Salvador: EDUFBA, 2010 .

QUEIROZ, D. M.; SANTOS, J. T. O impacto das cotas na Universidade Federal da Bahia. In: SANTOS, J. C. (Org.). Cotas nas universidades: análises dos processos de decisão. Salvador: Centro de Estudos AfroOrientais, 2012.

QUEIROZ, D. M.; SANTOS, J. T. As cotas na Universidade Federal da Bahia: história de uma decisão inédita. In: SANTOS, J. C. (Org.). Cotas nas universidades: análises dos processos de decisão. Salvador: Centro de Estudos Afro-Orientais, 2012. p. 41-76. 
SANTOS, J. T. D.; QUEIROZ, D. M. O impacto das cotas na Universidade Federal da Bahia (2004-2012). In: SANTOS, J. T. (Org.). O impacto das cotas nas universidades brasileiras (2004-2012). Salvador: Centro de Estudos Afro-Orientais, 2013. p. 37-65.

SANTOS, T.A.M. Cotas raciais ou cotas sociais? In: PEIXOTO, M.C.L.; ARANHA, A. V. (Orgs.). Universidade pública e inclusão social: experiência e imaginação. Belo Horizonte: Editora da UFMG, 2008.

SCHWARTZMAN, S. A questão da inclusão social na universidade brasileira. In: PEIXOTO, M.C.L.; ARANHA, A. V. (Orgs.). Universidade pública e inclusão social: experiência e imaginação. Belo Horizonte: UFMG, 2008.

SILVA, M. N. As cotas universitárias para negros no Brasil e o caso de Londrina. In: CHAIA, V.; MACHADO, E. (Org.). Ciências Sociais na Atualidade: tempo e perspectiva. São Paulo: Paulus, 2009. v. 4. p. 165-186.

SILVEIRA, P.R.C.; SILVEIRA, M.I.M. Da maioria silenciosa à minoria mobilizada: as tensões e contradições na implantação das ações afirmativas na universidade Federal de Santa Maria - RS. In: SANTOS, J. C. (Org.). Cotas nas universidades: análises dos processos de decisão. Salvador: Centro de Estudos Afro-Orientais, 2012. p. 41-76.

\section{TAVARNARO, V. G. Representações de justiça dos alunos do quinto} ano do curso de direito da UEPG a partir da análise do sistema de cotas raciais. Dissertação (Mestrado em Educação) - Universidade Estadual de Ponta Grossa, Ponta Grossa, PR, Brasil, 2009.

TESSLER, L. R. Ação afirmativa sem cotas: o programa de ação afirmativa e inclusão social da Unicamp. In: PEIXOTO, M. C. L.; ARANHA, A. V. (Orgs.). Universidade pública e inclusão social: experiência e imaginação. Belo Horizonte: Editora, 2008.

TRAGTENBERG, M.H.R. O processo de elaboração e aprovação do Programa de Ações Afirmativas da universidade Federal de Santa Catarina (2002-2007). In: SANTOS, J. C. (Org.). Cotas nas universidades: análises dos processos de decisão. Salvador: Centro de Estudos Afro-Orientais, 2012. p. 41-76. 
VALENTIM, D. F. D.; CANDAU, V. M. Ex-alunos negros cotistas da UERJ: os desacreditados e o sucesso acadêmico. Tese (Doutorado) Departamento de Educação, Pontifícia Universidade Católica do Rio de Janeiro, Rio de Janeiro, 2012.

VIANA, J.L.V.; BENTES, H.V. Mídia Brasileira como Instrumento de Racismo e Interdição do Negro no Contexto das Ações Afirmativas. Revista da ABPN, Florianópolis, v. 2, n. 4, p. 81-101, mar./jun. 2011.

WALTENBERG, F. D.; CARVALHO, M. Cotas aumentam a diversidade dos estudantes sem comprometer o desempenho? Revista Sinais Sociais, Rio de Janeiro, n. 20 set./ dez., 2012.

\section{ZARPELON, S. F.; CORDEIRO, M. J. de J. A. Indígenas cotistas}

ingressantes na UEMS em 2004: levantamento e análise das causas de evasão, face às ações de permanência desenvolvida pela instituição. UEMS. 2009. Disponível em: <http:/www.redeacaoafirmativa.ceao.ufba.br/uploads/ uems_artigo_2009_SFZarpelon_MJdeJACordeiro.pdf.> Acesso em: 12 nov. 2013.

Adriano de Lemos Alves Peixoto - Universidade Federal da Bahia Salvador | BA | Brasil. Contato: peixoto@hotmail.co.uk

Elisa Maria Barbosa de Amorim Ribeiro - Universidade Federal da Bahia Salvador | BA | Brasil. Contato: elisambr@hotmail.com Antônio Virgilio Bittencourt Bastos - Universidade Federal da Bahia Salvador | BA | Brasil. Contato: antoniovirgiliobastos@gmail.com

Maria Cecilia Koehne Ramalho - Universidade Federal da Bahia Salvador | BA | Brasil. Contato: cissa.ram@gmail.com 
